\title{
A Study on Achievement of Sustainable Development Goals from a Gender Equality Perspective
}

\author{
Pradeep Kumar Panda* \\ School of Social Sciences, IGNOU, India
}

*Corresponding author: Pradeep Kumar Panda, School of Social Sciences, IGNOU, India.

Received Date: August 10, 2018

Published Date: April 09, 2019

\begin{abstract}
The 2030 Agenda for Sustainable Development is a landmark agreement negotiated and approved by the 193 Member States of the United Nations. Comprised of 17 Sustainable Development Goals (SDGs), 169 targets and 232 indicators, it aims to address the economic, social, environmental and political dimensions of sustainable development in a comprehensive and integrated way. The SDG Agenda is clear that achieving gender equality is not only an important goal in and of itself but also a catalyst for achieving a sustainable future for all. Progress on gender equality has been highly uneven across the different dimensions of the 2030 Agenda. In some areas, such as girls' access to education, global improvement is undeniable yet insufficient, often leaving behind women and girls in the poorest households (SDG 4). In areas such as labor force participation (SDG 8) and innovation and knowledge creation (SDG 9), significant gender gaps remain, and progress has been minimal. In other cases, such as maternal mortality (SDG 3), progress is too slow and uneven to achieve SDG Target 3.1 by 2030. Similarly, while progress has been made towards eliminating the practice of female genital mutilation (FGM) (SDG 5), this is not enough to keep up with population growth, meaning the number of women and girls undergoing FGM is likely to rise over the next 15 years. Unless progress on gender equality is accelerated, the global community will not only fail to achieve SDG 5, it will also forgo the catalytic effect that gender equality can have for the achievement of the 2030 Agenda more broadly. This paper shows that across countries and regions, women and girls face tremendous structural barriers that impact all aspects of their lives. Eliminating gender-specific constraints, as well as other forms of discrimination with which they intersect, is hence critical.
\end{abstract}

Keywords: SDG; Development; Gender Equality; Issues; Challenges

\section{Introduction}

The 2030 Agenda for Sustainable Development is a landmark agreement negotiated and approved by the 193 Member States of the United Nations. Comprised of 17 Sustainable Development Goals (SDGs), 169 targets and 232 indicators, it aims to address the economic, social, environmental and political dimensions of sustainable development in a comprehensive and integrated way. Building on a long history of international human rights and gender equality commitments, its universal approach recognizes the common challenges faced by all countries, developed and developing alike, and reaffirms the responsibility of governments to address them. The 2030 Agenda is clear that achieving gender equality is not only an important goal in and of itself but also a catalyst for achieving a sustainable future for all [1,2].
While this bold vision has the potential to transform the lives of women and girls across the world, it is being implemented at a time of global uncertainty and multiple challenges. Climate change and environmental degradation are advancing at an unprecedented pace; the global economy remains volatile after nearly a decade of crisis; a shift towards exclusionary and fear-based politics is deepening societal divisions, breeding conflict and instability; and millions are being forcibly displaced due to conflict and humanitarian catastrophes. In the midst of global socio-economic and political turmoil, not only does the promise of gender equality remain unfulfilled but women's rights are also facing renewed resistance from different kinds of fundamentalisms [3]. 
This state of affairs presents a real test for the 2030 Agenda. At the same time, the mere fact that UN Member States have agreed to strive for a more equal world where development is based on sustainability, peace and human progress provides reason to be cautiously optimistic. The SDGs are especially important now as both a political agenda for global cooperation and a specific, timebound set of goals for all countries [4].

Women and girls are half of the world's population and as a result hold half of the world's human potential. When their lives are improved, the benefits reverberate across society. Access to decent work and regular income in the hands of women, for example, contribute not only to poverty reduction (SDG 1) but also support better education, health and nutrition outcomes for women and girls and those who depend on them (SDGs 2, 3 and 4). Similarly, eliminating all forms of violence against women and girls (Target 5.2) is not only an essential component of SDG 5 but also critical to ensuring healthy lives and well-being for people of all ages (SDG 3). Women subjected to sexual or physical intimate partner violence are 1.5 times as likely to become infected with HIV (Target 3.3). They are also almost twice as likely to experience depression and alcohol use disorders (Target 3.5). The health consequences of violence against women and girls extend to their children, who may witness the abuse and suffer long-term trauma that impacts their physical, emotional and social development [5].

Unless progress on gender equality is accelerated, the global community will not only fail to achieve SDG 5, it will also forgo the catalytic effect that gender equality can have for the achievement of the 2030 Agenda more broadly. This paper shows that across countries and regions, women and girls face tremendous structural barriers that impact all aspects of their lives. Eliminating genderspecific constraints, as well as other forms of discrimination with which they intersect, is hence critical [6].

\section{Achievement of 17 Sustainable Development Goals}

\section{SDG 1: No poverty}

Globally, there are 122 women aged 25-34 for every 100 men of the same age group living in extreme poverty. Unequal access to and control over economic resources lie at the root of women's poverty. Discriminatory legal frameworks and customary laws can place significant constraints on women's ability to earn an income by restricting their access to inheritance, land, property and credit as well as their mobility. But even where formal restrictions are removed, women face multiple barriers to their ability to move out of poverty. Labor market segmentation, gender wage gaps and unequal access to social protection remain a persistent source of economic disadvantage for women. Discriminatory social norms and women's disproportionate share of unpaid care work further hamper their ability to earn a living. As a result, women are less likely than men to have an income of their own, rendering them financially dependent on their partners and increasing their vulnerability to poverty [7].

UN Women partnered with the World Bank to produce new analysis, using the recently developed Global Micro Database (GMD) $[8,9]$. Building on the work of the Economic Commission for Latin America and the Caribbean (ECLAC) on the femininity index, the analysis for 89 countries looks at the prevalence of extreme poverty by sex, age and additional characteristics such as marital status and educational attainment and by differences in household composition (for example, mix of earners and non-earners by sex) $[10,11]$. It shows that, at the global level, the percentage of women and girls living in poor households (i.e., the female poverty rate) is $12.8 \%$, compared to $12.3 \%$ for men and boys. This is equivalent to a total of 330 million poor women and girls compared to 325 million poor men and boys. When adjusted for the fact that men outnumber women in the population, the results indicate that women globally are $4 \%$ more likely than men to live in extreme poverty, while the gender gap rises to $8 \%$ in Central and Southern Asia. At the regional level, extreme poverty rates are higher among women than among men in Central and Southern Asia, Latin America and the Caribbean, Oceania (excluding Australia and New Zealand) and sub-Saharan Africa. In Eastern and South-eastern Asia, women are less likely to live in extreme poverty than men. However, differences in extreme poverty rates by sex are small across regions and only statistically significant in Central and Southern Asia, where the rate is $15.8 \%$ for women compared to $14.5 \%$ for men.

Poverty rates are higher for children across the board compared to other age groups and decline relatively rapidly until the age of 24 . The shift in trend after age 24 coincides with the period of biological reproduction and family formation, during which parents and caregivers may face increased expenses while also experiencing a squeeze on their time. This is particularly true for women who struggle to combine paid work and caring for children or other dependents. As a result, women are particularly vulnerable to poverty-and gender gaps are widest during this phase of the life course. Globally, there are 122 women aged 25-34 for every 100 men of the same age group living in extreme poor households, and the figure rises to 132 women for every 100 men in Latin America and the Caribbean. By age 55, the percentage of poor women is lower than that of poor men and thus they are no longer overly represented among the poor. Further research is needed to understand gender differences in poverty among older women and men, as these vary substantially across countries [12].

\section{SDG 2: Zero hunger}

In nearly two thirds of countries, women are more likely than men to report food insecurity. An estimated 789 million people, $11 \%$ of the world's population, are undernourished. If trends persist, the goal of ending hunger by 2030 will be missed. Data collected by the Food and Agriculture Organization (FAO), using the Food Insecurity Experience Scale (FIES) in the context of the Voices of the Hungry project for 141 countries in 2014 and 2015, show that women are more likely to report food insecurity in nearly two thirds of the countries. Across regions, the highest prevalence of food insecurity is in sub-Saharan Africa, where more than half of the population is food insecure at moderate or severe levels. However, food insecurity is also prevalent in the largest economies in the world. In the United Kingdom, for example, 10\% of women and 9 per cent of men reported food insecurity [13].

While women generally report greater food insecurity, the gender gaps vary significantly across countries. Gender differences are greater than 3 percentage points and biased against women 
in nearly a quarter of the 141 countries sampled and against men in seven countries. In Albania, for instance, women were 4.4 percentage points less likely than men to say they struggled with regular access to food for themselves and their families. In Pakistan, however, food insecurity among women was a staggering 11 percentage points higher than that among men. Food insecurity results in poor health and decreased nutrient intake. This is a particular challenge for children as well as pregnant and lactating women, who often suffer from anemia as a result. A leading cause of maternal mortality, anemia was estimated to affect $29 \%$ of women aged 15-49 globally in 2011. The figure is higher for pregnant women (38\%). Prevalence rates are also generally higher among rural women, women living in the poorest quintile and women with lower levels of education.

\section{SDG 3: Good health and well being}

Maternal mortality has declined since 1990, but much too slowly to achieve Target 3.1 by 2030 . Globally, about 303,000 women died from pregnancy-related causes in 2015, resulting in a maternal mortality ratio (MMR) of 216 maternal deaths per 100,000 live births. At the regional level, sub-Saharan Africa has the highest MMR with 556 deaths per 100,000 live births and accounts for two thirds of all maternal deaths each year. Globally, the lifetime estimated risk of a woman dying from a maternity-related cause is 1 in 4,900 , but the ratio rises to 1 in 180 in developing countries and 1 in 54 in countries designated as fragile States, where health systems are often broken or overwhelmed. Maternal mortality ratios went down by 44\% between 1990 and 2015, a decline of $2.3 \%$ per year. However, achieving SDG Target 3.1 by 2030 will require a decline of at least $7.5 \%$ annually. To highlight the scale of the challenge, the largest declines in the MMR between 1990 and 2015 were observed in Eastern Asia (2.9\% annually), but this is still less than half the annual reduction that is needed to achieve the target. The United States is an outlier to the general downward trend among developed countries. Deaths related to complications from pregnancy or childbirth increased there between 2000 and 2014 from 18.8 to 23.8 per 100,000 .

The rates of death are particularly high among African American women as well as among low-income women and women residing in rural areas regardless of their race or ethnicity. Most maternal deaths can be prevented if mothers receive adequate antenatal and post-natal care, if deliveries are attended by skilled health professionals and if women have adequate access to medical care for health conditions linked to elevated risk of obstetric complications, including those arising from unsafe abortions. Expanding access to quality health care and ensuring universal access to sexual and reproductive health and rights for women and girls is therefore essential for reducing maternal mortality rates. Globally, deliveries attended by skilled health professionals are increasing, from $61 \%$ in 2000 to $79 \%$ in 2016. But accelerated efforts are also needed in related areas such as family planning, including access to modern contraceptive methods, if Target 3.1 is to be achieved by 2030 .

\section{SDG 4: Quality education}

Despite recent progress, girls continue to face significant disadvantages in education. As many as $48.1 \%$ remain out of school in some regions. Data from 2015 show that $90.3 \%$ of girls of primary school age were enrolled in school that year, up from $82.2 \%$ in 2000 , compared to boys at $91.9 \%$ in 2015 and $87.6 \%$ in 2000 . The gender gap has thus narrowed globally by 3.8 percentage points over the last 15 years. At the same time, between 2000 and 2015, girls have made significant strides compared to boys, reducing the primary out-of-school rate, a key indicator of exclusion from education, from $17.8 \%$ to $9.7 \%$ compared to a reduction from $12.1 \%$ to $8.1 \%$ for boys. However, despite such progress, girls continue to face significant disadvantages in education: It is estimated that 15 million girls will never get the chance to learn to read or write in primary school compared to about 10 million boys. In secondary education, girls have nearly caught up with boys at the global level, with net enrolment rates rising from $53.1 \%$ to $64.8 \%$ for girls compared to an increase from $57.7 \%$ to $65.3 \%$ for boys between 2000 and 2015 . Nevertheless, in some regions adolescent girls are more likely than boys to be excluded from education (though in others boys risk being disadvantaged). In sub-Saharan Africa and in Western Asia and Northern Africa, $48.1 \%$ and $25.7 \%$ of adolescent girls are out of school compared to $43.6 \%$ and $21.7 \%$ of boys, respectively. Poverty plays a key role in driving exclusion from education. The high rates of illiteracy, among other factors, contribute to deprivations in other areas, including inferior employment opportunities.

\section{SDG 5: Gender equality}

Removing discriminatory laws and putting in place legislation that promotes gender equality is a prerequisite to achieving equality between the sexes [14]. Over the past 25 years, progress has been made through, for example, legislation prohibiting discrimination based on sex with respect to inheritance and citizenship, laws that guarantee equality within the family and laws that address domestic violence [15]. However, while progress has been significant, discriminatory constitutional and legislative provisions remain in place in many countries, leaving women without protection or legal basis to claim their rights.

Under international human rights law and agreements, notably the Convention on the Elimination of All Forms of Discrimination against Women (CEDAW) and the Beijing Declaration and Platform for Action, States have committed to eliminating discrimination against women and promoting gender equality, including in the area of legal frameworks. The five-year review and appraisal of the Beijing Platform for Action (Beijing + 5) established 2005 as the target date for the repeal of laws that discriminate against women. This deadline has come and gone and still data from 2016 show that in 18 countries husbands can legally prevent their wives from working, in 39 countries daughters and sons do not have equal inheritance rights, laws protecting women from domestic violence are lacking in 49 countries and in 37 countries rape perpetrators are exempt from prosecution if they are married to or subsequently marry the victim.

1 in 5 women and girls aged 15-49 reported experiencing physical and/or sexual violence by an intimate partner in the previous 12 months. Available comparable data from 87 countries show that $19 \%$ of women and girls aged 15-49 have experienced physical and/or sexual violence by an intimate partner in the past 
12 months. Oceania (excluding Australia and New Zealand) is the region with the highest 12 -month prevalence of intimate partner violence (IPV), with up to $40 \%$ of women aged $15-49$ reporting having experienced this. Women in the same age group living in Europe and Northern America had the lowest prevalence rate, estimated at $6 \%$.

Trend data on violence against women and girls are not widely available. Surveys are often only available for one point in time or use different methodologies, hindering comparability over time between and within countries. Comparable data for 17 countries on prevalence of physical or sexual IPV against women (aged 15-49) in the 12 months prior to the survey suggests prevalence is generally falling, especially in countries with the highest prevalence. In the Democratic Republic of the Congo, for example, there was a significant decrease from 59\% (2007) to 37\% (2013-2014). Despite the general downward trend, however, a statistically significant increase in IPV prevalence is observed in 5 of the 17 countries. For example, in the Dominican Republic, prevalence rose from $12 \%$ in 2007 to $16 \%$ in 2013.

Women and girls of all ages are vulnerable to violence. Based on comparable data from 50 countries, an estimated 15 million adolescent girls (aged 15-19) report experiencing forced sex in their lifetime. Data from 28 countries also show that 9 in 10 adolescent girls who have experienced forced sex report being victimized by someone close or known to them. In addition, adolescent girls and young women face the risk of violence in other settings such as in school or on university campuses. It is estimated that 246 million girls and boys globally have experienced school-related violence and one in four girls report never feeling safe using school latrines. In a survey across 27 universities in the United States in 2015, $23 \%$ of female undergraduate university students reported having experienced sexual assault or sexual misconduct.

Every year, 15 million girls under the age of 18 are forced into marriage. According to 2017 figures, an estimated 750 million women and girls were married before the age of 18. Every year, 15 million girls under the age of 18 are forced into marriage. Unless progress on this target is accelerated, the figure will grow to 16.5 million in 2030 and to over 18 million in 2050. Among regions with available data, Central and Southern Asia has the highest rates of child marriage, with 16 per cent of women currently aged 20-24 married before they turned 15 and 43 per cent before age 18, while Eastern and South-eastern Asia and Europe and Northern America have the lowest child marriage prevalence rates at $15 \%$ and $8 \%$, respectively. Similarly, these regions also register the lowest rates of marriage before age 15 , at $2 \%$ and $0 \%$, respectively.

Women do 2.6 times the unpaid care and domestic work that men do. Data from 83 countries and areas show that women perform most of the domestic work, such as cooking and cleaning, and are the main caregivers of children and adults needing care. Women on average spend $18 \%$ of their day on total unpaid care and domestic work, while men allocate $7 \%$ of their day. Disaggregated by age, the time spent on unpaid care and domestic work is highest among women aged 25-44, compared to women aged 15-24 and 45-64. This peak in the care burden for women coincides with the period during which they are most likely to have young children at home. Where data are available, the evidence points to women with younger children doing more unpaid work, including care work, than those without children. Differences among women also vary by other factors including household income, whether there is access to drinking water and fuel in the home, and policies related to childcare.

The expectation that care work is a women's responsibility starts at an early age. A study of 33 countries shows that girls aged 7-14 do more household work than boys the same age and perform other tasks, including care of younger siblings. The division of labor into 'women's work' and 'men's work' continues for many women as they start their own families and reverberates into the workforce (SDG 8). Gender stereotypes influence the kind of work women do outside of the home, the conditions under which that work is offered and the payment they receive. It also impacts women's ability to engage in other aspects of public life, including political participation (Target 5.5).

Despite progress, women remain under-represented in parliaments worldwide. While there has been progress over the last decade, women continue to be under-represented in parliaments worldwide. Globally, women hold $23.7 \%$ of parliamentary seats, an increase of 10 percentage points since 2000. At the country level, only in Rwanda (61\%) and the Plurinational State of Bolivia (53\%) do women occupy more seats in parliament than men. The use of electoral gender quotas and other temporary special measures has raised the shares of women's representation in national decision-making bodies in many countries. In sub-Saharan Africa, quotas have been shown to increase women's representation in politics, while countries in the region with few quotas experienced considerable setbacks in 2016. In Latin America, gender quotas, coupled with quotas targeting racial minorities, have increased the representation of traditionally marginalized groups. Yet, despite the demonstrated impact, less than half of countries around the world have some form of legislated quota in place. While quotas and other TSMs are effective at promoting women's political representation, periodic reviews are needed to ensure they do not inadvertently impose a ceiling on women's representation [16].

Women are under-represented in senior and middle management positions in all countries with available data. In terms of decision-making power within government, large enterprises and institutions, women are under-represented in senior management and middle management positions. Despite some progress, the proportion of women in senior and middle management remains below $50 \%$ in all countries except the Dominican Republic, where it reached almost 53\% in 2015. Globally, less than a third of senior and middle management positions are held by women. Due to break in statistical series (e.g., based on revisions to methodology), change in the female share of employment in senior and middle management is difficult to assess with certainty. Nevertheless, trend data, available for 35 countries, point to improvements in some countries but falling shares in others. Over the last decade, 11 countries have seen the proportion of women in senior and middle management increase by 7.4 percentage points on average. However, the proportion declined (by more than 3 percentage 
points) in 8 countries. In another 16 countries, the change in the share of women in managerial positions has not exceeded 3 percentage point.

Women and adolescent girls face many challenges and risks with respect to their sexual and reproductive health and rights. Only 52\% of women married or in a union freely make their own decisions about sexual relations, contraceptive use and health care at present, there is no comprehensive global database on laws regarding sexual and reproductive health and reproductive rights, but data on women's autonomy in decision-making regarding their sexual and reproductive health and rights are available for a subset of countries. Based on data from 45 countries, mostly in sub-Saharan Africa, only 52\% of women aged 15-49 there who are married or in union make their own informed decisions about sexual relations and the use of contraceptives and health services.

For adolescent girls, in addition to barriers to access, sexual and reproductive health and rights are also compromised by lack of comprehensive sexuality education and harmful practices. Complications related to childbirth and pregnancy are among the leading causes of death for girls aged 15-19. States have an obligation to provide accessible, quality and affordable sexual and reproductive health services. Yet, even when services are available, cost is often a hurdle that women find difficult to overcome. In a sample of 65 countries, cost was repeatedly identified as a factor that hampered women's ability to access health care. For example, this was the case for 11\% of women in Egypt and 86\% in São Tomé and Príncipe.

Data on women's role in the agricultural sector point to deep gender inequalities. Women are far less likely to be agricultural land holders: Their share ranges from $0.8 \%$ in Saudi Arabia to 51\% in Cabo Verde, with an overall global share of $12.8 \%$. Available evidence shows that, when women own land, their plots are generally smaller and of lower quality than men's and their rights to the land are less secure.

Women lag behind men in Internet access and mobile phone ownership. Access to the Internet is increasing exponentially. The technology is being used to communicate and share information in school settings, in workplaces and at home. But women are not being reached at the same pace as men. In 2017, the proportion of women using the Internet globally was 5.9 percentage points lower than men's. Eastern and South- eastern Asia has the largest gender gap: Only $28 \%$ of women had access to the Internet in comparison to $42 \%$ of men. In Europe and Northern America, where Internet penetration is high for both women and men, usage among women (75\%) was lower than among men (82\%). Only in Latin America and the Caribbean region were women's usage rates higher than men's: $67 \%$ compared to $65 \%$. Despite the potential benefits, an estimated 1.7 billion women in low- and middle-income countries do not own a mobile phone: Women are $14 \%$ less likely than men to own one [17].

\section{SDG 6: Clean water and sanitation}

Women and girls are responsible for water collection in $80 \%$ of households without access to water on premises. Although billons have gained access to basic water and sanitation services since 2000, progress has been uneven and some of the gains are increasingly fragile as water stress intensifies due to climate change, unsustainable consumption and intensified agricultural activity and land degradation [18]. In 2015, 2.1 billion people lacked access to safely managed drinking water services (i.e., water that is accessible on premises, available when needed and free from contamination). In fact, it is estimated that only $71 \%$ of the world's population uses safely managed services. Oceania and subSaharan Africa have the highest proportion of people who rely on unsafe water sources, including surface water from rivers, streams or ponds as well as unprotected open wells. Across the developing world, urban access to basic water is higher than rural access and high- income groups have significantly better access than lowincome groups. In Pakistan, for example, $41 \%$ of urban households have access to safely managed drinking water compared to $32 \%$ of rural households; large differences also exist across income and ethnic groups.

When safe drinking water is not available on premises, the burden of water collection and treatment largely falls on women and girls, who are forced to allocate significant amounts of time and limit their engagement in other activities such as paid work and education. Survey data for 61 countries show that in $80 \%$ of households without access to water on premises, women and girls are responsible for water collection. This is particularly true for the poorest households in rural areas. In Benin, for instance, the average time to reach a water source for those who do not have it on premises is 21.5 minutes, yet this time varies widely across households: In rural households it takes an average of 24 minutes, while in urban households it takes 16 . Among the poorest households, the average time is 26.5 minutes, compared to 12.5 among the richest.

\section{SDG 7: Affordable and clean energy}

Access to affordable and clean energy is crucial for combating climate change as well as for promoting poverty alleviation, sustainable growth, industrialization and access to water. Yet, 1.1 billion people worldwide lack access to electricity and more than 3 billion rely on combustible fuels such as coal, kerosene and biomass (wood, charcoal, agricultural residues and animal dung) as their primary source for cooking, lighting and other household energy needs. More than half of all households globally rely on solid fuels that put women's health and livelihoods at risk. Across 92 countries, $64 \%$ of households rely on solid fuels, including wood, crop wastes, charcoal, coal or dung. Often, these and other unclean fuels (including kerosene) are used with inefficient technologies such as open fires and leaky stoves that lead to high levels of household air pollution [19].

The use of solid fuels for cooking and heating is highest in sub-Saharan Africa and Oceania, where $85.7 \%$ and $86.2 \%$ of households, respectively, rely on it. Households in Northern Africa and Western Asia generally show the lowest reliance on solid fuels, at $12.4 \%$. Wealth and rural-urban disparities are important across regions, with low-income and rural households relying on solid fuels to a much greater extent than high-income and urban 
households [20]. The health and environmental impacts of unclean fuels and inefficient technologies can be devastating for women and children, who usually spend more time in the home. In 2012, indoor air pollution caused 4.3 million premature deaths, with women and girls accounting for 6 out of every 10 of these. As a cause of noncommunicable diseases such as chronic obstructive pulmonary disease, lung cancer and heart disease, indoor air pollution has become a major environmental health concern [21].

Besides the adverse health effects associated with indoor air pollution, the reliance on solid fuels means that women and girls spend a significant amount of time collecting fuel. Girls in households that use solid fuels for cooking spend 18 hours a week on average gathering fuel, compared to 5 hours a week in households using clean fuels. A recent study of 22 African countries estimates that women and girls spend an average of two hours each day just collecting fuel, an arduous task that puts them at risk of injury, animal attacks and physical and sexual violence and impinges on girls' education and leisure time.

\section{SDG 8: Decent work and economic growth}

Globally, the labor force participation rate among prime working-age women (aged 25-54) stands at 63\% compared to $94 \%$ among their male counterparts, with stark variations across regions. However, gender gaps in LFPR vary tremendously across regions and countries. The widest gaps, of nearly 60 percentage points, are found in Northern Africa and Central, Southern and Western Asia, where female participation rates are also less than $40 \%$. Over the last 20 years, the global gender gap in LFPR among prime working-age adults (aged 25-54) has remained relatively unchanged with the notable exception of Latin America and the Caribbean. Since the 1980s, more than 70 million women have entered the labor force in this region, resulting in an increase in their participation rate. Data since 1997 show the LFPR of women aged 25-54 increased there from 57\% to 68\%. Modest increases in the female prime working-age LFPR have also taken place in subSaharan Africa and the gender gap has declined, but this has taken place against a backdrop of falling participation rates for men. Central and Southern Asia is the only region where prime workingage women's LFPR has fallen consistently since 1997 , from $42 \%$ to $37 \%$, according to the latest 2017 estimates. Countries in the region recording the largest declines in LFPR of women aged 25-54 are Kyrgyzstan (14.7 percentage points), Bangladesh (10.3 percentage points) and India (8.1 percentage points).

\section{SDG 9: Industry, innovation and infrastructure}

Globally, less than a third of all research positions are held by women. Globally, women represent $28.8 \%$ of researchers, but with wide variations across regions. In developing countries, there are three times more men than women researchers, while in developed countries there are twice as many. At the regional level, there are wide variations, with high levels of representation observed in Australia and New Zealand (52\%) and Latin America and the Caribbean (47\%) and low levels in Eastern and South-eastern Asia, Central and Southern Asia and sub-Saharan Africa, where women make up, on average, $25 \%, 33 \%$ and $31 \%$ of researchers, respectively. There are wide variations across countries, with women registering the highest share of researchers in Thailand (56\%) and Venezuela (55\%) but only $10 \%$ or less in countries such as Nepal and Togo. Only about one in five countries have achieved gender parity, whereby $45 \%$ to $55 \%$ of researchers are women.

\section{SDG 10: Reduced Inequalities}

Across countries, women are more likely than men to live on less than $50 \%$ of the median income. The latest available estimates of global inequality suggest little change in the distribution of income among the different countries in the world. Global inequality has fallen in recent years, but under-reporting of top incomes suggests the downward trend is at best marginal. The Global Gini Index stood at $70.5 \%$ in 2008 but could be as high as almost $76 \%$ when adjusted for the under-reporting. It is estimated that between 1988 and $2008,44 \%$ of the global income went to the top $5 \%$, while the poorest saw little income gains in either relative or absolute terms. Global economic growth has contributed to a decline in poverty but has done so unevenly, with polarizing effects on the distribution of income within countries. While the extent of global inequality between countries can be difficult to discern, the rise of inequality within countries is well documented [22].

In Organization for Economic Cooperation and Development countries, the average income of the richest $10 \%$ of the population has grown over the last 25 years from seven to nine times the average income of the poorest $10 \%$, and income inequality is at its highest level for the last half century. In developing countries, income inequality rose by $11 \%$ between 1990 and 2010. Inequality within the household, for example, between women and men, is a strong contributing factor to the overall income inequality in society, accounting for up to $30 \%$ according to a recent study. Women generally earn less than men, have access to fewer assets and consequently have less wealth than men. Across countries, women are more likely than men to live below $50 \%$ of the median income. Data shows the differences by sex in the proportion of people living on less than $50 \%$ of the median income for a select set of countries for which data are available. The largest gender differences are found in the Republic of Korea, South Africa and the United States. In all the countries in the sample, single-mother households are most likely to fall below the $50 \%$ median income mark. The United States stands out with the highest proportion of single- mother households (44\%) falling below the $50 \%$ median income mark (followed by Brazil and South Africa with $43 \%$ and Luxembourg, Italy and Spain with $42 \%, 41 \%$ and $40 \%$, respectively).

\section{SDG 11: Sustainable cities and communities}

At present, more than half of the world's population lives in urban settlements. Estimates suggest that by 2030, urban areas will house $60 \%$ of all people, with one in every three living in cities of at least half a million inhabitants. Women living in urban slums endure many hardships, with basic needs such as access to clean water and improved sanitation facilities often going unmet. In $2014,23 \%$ of the urban population lived in slums, down from $28 \%$ in the year 2000. However, in sub-Saharan Africa, more than half (56\%) of urban dwellers continue to live in slum conditions. In $67 \%$ of the countries with available data, more than half of the female urban population aged 15-49 lives in slums [23]. 
That is, more than $50 \%$ of urban women live in conditions where they lack at least one of the following: access to clean water, improved sanitation facilities, durable housing or sufficient living area. Many of these women endure not just one deprivation but have several of these four basic needs unmet. In 30\% of countries-most of them located in sub-Saharan Africa-more than $5 \%$ of all women living in cities had three of these four basic needs unmet at once. In Chad, Democratic Republic of the Congo, Ethiopia, Madagascar, Mozambique, São Tomé and Príncipe, Uganda and United Republic of Tanzania, more than $10 \%$ did. In Chad, the proportion of urban women who lacked access to three of the four amounted to a staggering $24.8 \%$. In countries where slum housing is particularly widespread among urban women, the two most prevalent forms of unmet household needs are a lack of durable housing materials and lack of improved sanitation facilities, which impose significant risks and burdens on women, as they spend more time in the home and are thus more exposed to hygiene and health risks. Although not as pervasive as lack of sanitation and durable housing, the inaccessibility of clean water and the overcrowding experienced by many slum dwellers make families more vulnerable to illness and increase the time burden on women in charge of water collection and caring for the sick.

\section{SDG 12: Responsible consumption and production}

Unsustainable production and consumption patterns are the key drivers behind the progressive depletion of natural resources and the rapid advance of climate change, which are taking a disproportionate toll on the livelihoods of women and girls, particularly in developing countries. However, these take place in an increasingly unequal world where as many as 767 million people live on less than US $\$ 2$ a day and struggle to cover basic consumption needs. Travel 'choices' and their sustainability are shaped by gender and other inequalities. Around the world, people are consuming more goods and leaving greater material footprints. Globally, per capita, this increased from 8 metric tons in 2000 to 10.1 metric tons in 2010 .

It increased in almost all regions, but the material footprint per capita of developed regions far exceeds that of developing regions. In other words, much of the raw material extracted globally goes to serve the consumption needs and habits of individuals in developed regions. Passenger cars, which are heavily consumed goods, leave large material and carbon footprints and are a major contributor to air pollution. Moreover, driving is not only an unsustainable but also a highly unequal travel 'choice'. For example, while $85-89 \%$ of households own a car in countries such as Italy, Germany and the United States, this is true for only 2-3\% of households in Bangladesh, Uganda and Viet Nam. Even in emerging economies such as Mexico and South Africa, only about a third of households own a car. Within developing countries, too, travelling by car is a choice available mostly to a privileged minority. In Brazil, for example, two thirds of high-income households own a car compared to only one quarter of low-income households.

While systematic sex-disaggregated data on modes of transport is lacking, existing evidence suggests that women are less likely to drive than men and more reliant on public transport. Where reliable and affordable public transport options are lacking, the main mode of transport for poor people, and for women in particular, is walking. Data from Johannesburg-where race and income strongly correlate-show, for example, that white women and men drive cars for over $50 \%$ of their trips. African and colored women, in contrast, literally never have a car available to drive (although about $7 \%$ of African men and over $20 \%$ of colored men do) and are dependent instead on walking (for just under $40 \%$ of trips).

\section{SDG 13: Climate action}

Human-induced climate change is having a profound impact on the natural ecosystems on which all life depends. Significant changes in the temperature of land and water bodies are increasing the frequency and intensity of extreme weather events and natural disasters, including droughts, fires and floods. This has a disproportionately negative impact on women and children, who are 14 times as likely as men to die during a disaster. Women's livelihoods are also impacted by the adverse effects of climate change, including through reduced crop and forest yields and acidification of the ocean, which negatively affects the harvesting of marine life. Globally, women are heavily engaged in agriculture (SDG 2), are largely in charge of foraging (SDG 7 and 15) and fetching water (SDG 6) and play an important role in small-scale fisheries and seafood marketing (SDG 14)-all areas facing disruption. Mitigating actions are urgently needed to protect the health and livelihoods of all people adversely impacted by climate change.

Poor women's livelihoods are compromised by shrinking agricultural yields. Those who are heavily dependent on local natural resources for their livelihood, such as poor women living in rural areas and indigenous populations, are disproportionately affected by climate change. Globally, one fourth of all economically active women are engaged in agriculture. Especially in heavily agriculture-dependent Asia and Africa, the majority of employed women work in agriculture, and agriculture-related occupations represent a relatively larger share of women's employment than men. Projections indicate that by 2050 , climate change will have reduced the production of rice, wheat and maize by $15 \%, 49 \%$ and $9 \%$, respectively, in South Asia and by 15\%, 36\% and 7\% in subSaharan Africa, resulting in higher food prices and heightened food insecurity.

Reductions in crop yields will also affect food distribution within households, with potentially gender-unequal nutritional outcomes. The time needed for food production, processing and preparation, to which women already contribute $60-70 \%$ of their total labor time, is also likely to increase as a result of shrinking agricultural yields. Many female agricultural workers also face severe inequalities in their access to land, credit and essential inputs such as fertilizers, irrigation, technology, information and markets. Thus, climate change adaptation and mitigation practices requiring the use of technical advances on heat-resistant and waterconserving crop varieties are also less likely to reach them.

\section{SDG 14: Life below water}

The sustainable management of oceans, seas and marine resources is essential for the protection of our planet and supports 
the livelihoods of an estimated $12 \%$ of the world's population, or nearly 1 billion people. Oil spills, plastic waste, raw sewage, pollutants from industrial runoff and methylmercury from coal burning and mining are increasingly contaminating the world's oceans and inland waters. These pollutants impinge on women's and men's livelihoods and health as well as the health of their children. However, there is generally a lack of data and analysis of gender in relation to marine resources. In fact, none of the targets of SDG 14 address gender equality or the relation of marine resources to the livelihoods of women and men, including the role they can play in food security, employment and poverty reduction [24].

Fishing and aquaculture are critical for women's livelihoods, but occupational segregation looms large. Widespread occupational segregation exists in the fishing and aquaculture industries. While men are mostly involved in fish and aquaculture harvesting (81\% of workers in 2014), women are overwhelmingly involved in secondary fields such as fish processing, marketing and fishing machinery maintenance (90\%), which are often low paid or unpaid, and they face significant barriers to accessing financial resources and entrepreneurial support. The degree of women's reliance on fishing and aquaculture, both inland and open water, varies widely across regions. For instance, $20.3 \%$ of those involved in fisheries and aquaculture in Oceania are women, while the figure is $0.4 \%$ in Northern African and Western Asia. Women are a much greater share of those involved in onshore tasks, for example, in some regions, up to $60 \%$ of those involved in seafood marketing and $72 \%$ of those involved in aquaculture production are women. Lack of access to resources, including technology to keep fish fresh, means that women sustain large losses post-harvest. Furthermore, management is overwhelmingly male-dominated. In the maritime industry, which includes jobs from fishermen and brokers to marine administration and pollution mitigation specialists, women comprise only $2 \%$ of the workforce and are largely absent from decision-making positions. In 2016, only one of the top 100 seafood companies was run by a woman, and $54 \%$ of all seafood companies analyzed had no women on the board. Addressing the specific constraints faced by women engaged in fisheries and the fishing industry should be an integral component of strategies to achieve SDG 14. Evening out the power imbalances could also enable women to play a key role in marine conservation.

\section{SDG 15: Life on Land}

Women, particularly those from landless and land-poor households, are most affected by deforestation. It is estimated that 1.6 billion people around the world depend on forests for their livelihoods. Between 1990 and 2015, forest areas diminished from $31.7 \%$ of the Earth's total landmass to $30.7 \%$, mostly due to the conversion of forest land into agriculture and infrastructure. This amounts to a loss of 3.3 million hectares per year between 2010 and 2015 alone. Due to their lack of access to private land, poor rural women depend more than men on common pool resources such as forests and commons. Their responsibility for meeting household food and fuel needs means that they are particularly affected by the depletion of forests. A study in Malawi found deforestation was forcing elderly women to walk more than 10 kilometers a day to collect fuel wood. In Zambia, women spend on average 800 hours a year on the same task, and in the United Republic of Tanzania, they spend 300 hours a year. The expropriation of land for commercial purposes, which has intensified in recent years, is exacerbating this problem. Women's specific knowledge and dependence on forests makes them key contributors to forest conservation. Research shows that the presence of a critical mass of women (between 25$33 \%$ ) in community forestry institutions has a positive impact on forest condition and regeneration and strengthens their political agency [25].

\section{SDG 16: Peace, justice and strong institutions}

Female homicides, rape and other forms of violence against women are pervasive during and after conflict. Although the vast majority of global homicide victims are men, almost half of all women victims of intentional homicide in 2012-the latest year with available data-died at the hands of an intimate partner or family member, compared to $6 \%$ of the murdered men: Almost 44,000 women were victims of intentional homicide by an intimate partner that year, compared to 20,000 men [26,27]. According to the latest available estimates, the global female homicide rate stands at 2.3 per 100,000 , although figures vary widely across and within regions. The largest regional average is registered in Latin America and the Caribbean, with the highest rates in countries in Central America. High rates of female homicide are also observed in sub-Saharan Africa, with conflict and post- conflict countries in the region showing some of the highest rates [28].

In times of conflict, rates of homicide and other forms of violent crime increase significantly. While men are more likely to be killed on the battlefield, women are disproportionately subjected to sexual violence, singled out for abduction, tortured and forced to leave their homes. Targeted killings, rape and other forms of violence against women are often used as weapons of war. In conflict and postconflict countries, the proportions of female homicide victims are usually larger than the regional averages. For instance, the conflict or post-conflict States of Lesotho in sub-Saharan Africa, Papua New Guinea in Oceania and Kyrgyzstan in Central and Southern Asia are all at the top of their regional distributions.

Many conflict and post-conflict countries (Democratic Republic of the Congo, Nepal and Uganda, among others) are also those with some of the highest sexual violence rates worldwide. The likelihood of sexual violence being committed by police or military personnel is also higher during and after conflict. In Liberia, for instance, where two civil wars have claimed the lives of thousands and forced many to flee, the share of victims of sexual violence reporting having been assaulted by national security personnel surpasses $8 \%$, the largest among the countries with available data.

\section{SDG 17: Partnership for goals}

Achieving the SDGs for women and girls requires an enabling environment and a stronger commitment to partnership and cooperation. In 2012, financial resources flowing out of developing countries were 2.5 times the amount of aid flowing in, and gender allocations paled in comparison to these outflows. Target 17.3 calls for increased mobilization of financial resources for developing countries. Monitoring this target from a gender equality perspective 
requires assessing the extent to which financial resources from multiple sources are being mobilized to support developing countries and how much of these resources are designated for gender equality commitments. However, of all the resources coming into developing countries, overseas development aid (ODA) is the only one that can currently be tracked from a gender perspective $[29,30]$. Of the US $\$ 114$ billion in ODA commitments coming into developing countries in 2014-2015, US $\$ 40.2$ billion had a focus on gender equality. The sectors that received the most for genderrelated programming were government and civil society (18\%), education $(10 \%)$ and population and reproductive health $(10 \%)$.

Much less was committed to gender equality in the economic and productive sectors-for example, only $2 \%$ each were committed for business and banking. While ODA remains an important source of aid to low-income countries, non-ODA flows have gained importance over the past years. Data shows diverse sources of financing coming in, but equally important is the amount that is simultaneously flowing out. In 2012, developing countries received US $\$ 1.3$ trillion in aid, investment and income from abroad but US $\$ 3.3$ trillion flowed out in the form of interest payments on foreign debt, foreign investment, repatriated income and capital flight. It is estimated that $84 \%$ of these net resource transfers are accounted for by unrecorded capital flight, including illicit outflows. This loss in resources reduces the capacity of countries to transform their economies, protect their environments and invest in their people. Aid committed to gender equality, while important, is too limited to compensate for the loss in revenue that could otherwise have been invested in infrastructure and services that benefit women and girls.

\section{Conclusion}

Progress on gender equality has been highly uneven across the different dimensions of the 2030 Agenda. In some areas, such as girls' access to education, global improvement is undeniable yet insufficient, often leaving behind women and girls in the poorest households (SDG 4). In areas such as labor force participation (SDG 8) and innovation and knowledge creation (SDG 9), significant gender gaps remain, and progress has been minimal. In other cases, such as maternal mortality (SDG 3), progress is too slow and uneven to achieve SDG Target 3.1 by 2030. Similarly, while progress has been made towards eliminating the practice of female genital mutilation (FGM) (SDG 5), this is not enough to keep up with population growth, meaning the number of women and girls undergoing FGM is likely to rise over the next 15 years.

A revolution in democratic governance is needed for women and girls to claim their rights and shape sustainable development. Spaces for public debate and democratic decision-making must be created to define national priorities, identify what is working well and where the gaps are, agree on pathways for transformative change and determine the roles and responsibilities of different actors [31].

At the global level, open consultation throughout the post-2015 process engaged and mobilized people, countries and organizations to identify common priorities and navigate tensions. Women's rights organizations were extremely effective in building coalitions and alliances across different interest groups to put gender equality at the centre of the new agenda. Such participatory processes and strategic alliances are also needed to ensure effective and genderresponsive implementation, follow-up and review. The systematic monitoring of gender equality outcomes, policies and processes at the national, regional and global levels can contribute to catalyzing action, translating global commitments into results and strengthening accountability for actions or omissions by different stakeholders $[32,33]$.

Despite increasing attention to gender statistics in recent decades, the report identifies pressing challenges that stand in the way of systematic, gender-responsive monitoring. These include the uneven coverage of gender indicators across goals and targets; the absence of internationally agreed standards for data collection; and the uneven availability of gender statistics across countries and over time [34].

Delivering on the gender equality commitments of the 2030 Agenda requires mobilizing and allocating sufficient resources for policies and programmers that contribute to their achievement. As countries roll out their national implementation strategies, it is paramount that investments in these and other strategic areas are prioritized. It is also important that policies and programmers are aligned with the principles of the 2030 Agenda, including human rights principles such as equality, non-discrimination and universality $[35,36]$.

Gender-responsive processes and institutions are critical to turn the gender equality promises of the 2030 Agenda into action and to ensure that progress is monitored in a transparent and accountable way. States have committed to follow-up and review processes that are open, inclusive, participatory and transparent, as well as people-centered, gender- sensitive, respectful of human rights and focused on those who are furthest behind.

\section{Conflict of Interest}

No Conflict of Interest.

\section{Acknowledgement}

None.

\section{References}

1. Benería L, C D Deere, N Kabeer (2012) Gender and International Migration: Globalization, Development, and Governance. Feminist Economics 18(2): 1-33.

2. De Henau J (2015) Costing a Feminist Plan for a Caring Economy: The Case of Free Universal Childcare in the UK. Open Discussion Papers in Economics No. 79, The Open University, England, UK.

3. Elson D (2006) Budgeting for Women's Rights: Monitoring Government Budgets for Compliance with CEDAW. New York: United Nations Development Fund for Women (UNIFEM), USA.

4. O'Neil T, A Fleury, M Foresti (2016) Women on the Move: Migration, Gender Equality and the 2030 Agenda for Sustainable Development. Briefing paper, July. Overseas Development Institute (ODI), London.

5. Budlender D (2010) Time Use Studies and Unpaid Care Work. New York and Abingdon, UK: Routledge/ United Nations Research Institute for Social Development, UK.

6. Burt Z, K Nelson, I Ray (2016) Towards Gender Equality through Sanitation Access. Discussion UN Women, New York, USA, p: 1-12. 
7. Chen M A (2016) Expanding the Economic Potential of Women Informal Workers. Background paper for the UN Secretary-General's High-Level Panel on Women's Economic Empowerment.

8. Levien M (2017) Gender and Land Dispossession: A Comparative Analysis. Discussion, UN Women, New York, USA, p: 1-15.

9. Sen G (2017) The SDGs and Feminist Movement Building. Background paper for the Research and Data Section. UN Women, New York, USA.

10. Alkire S, E Samman (2014) Mobilising the Household Data Required to Progress toward the SDGs. OPHI Working p: 72.

11. Esquivel V (2016) Power and Sustainable Development Goals: A Feminist Analysis. Gender \& Development 24(1): 9-23.

12. Stotsky J (2016) Gender Budgeting: Fiscal Context and Current Outcomes. IMF Working Paper WP/16/149. International Monetary Fund, Washington,USA.

13.FAO (2010) Gender and Land Rights: Understanding Complexities; Adjusting Policies. Economic and Social Perspectives Policy Brief. FAO, Rome, Italy.

14. Beales S, G Gelber (2017) Gender Equality and the SDGs: An Analytical Review of Evidence on How Gender Equality Interacts and Interlinks with Other SDG-Related Areas. Background paper for the Research and Data Section. UN Women, New York, USA.

15. Agarwal B, P Panda (2007) Toward Freedom from Domestic Violence: The Neglected Obvious. Journal of Human Development 8(3): 359-388.

16. Morris M (2016) Women's Leadership Matters: The Impact of Women's Leadership in the Canadian Federal Public Service. Ottawa: Centre for Women in Politics and Public Leadership, Carleton University, Canada.

17. GSMA (2015) Connected Women 2015: Bridging the Gender Gap-Mobile Access and Usage in Low-and Middle-Income Countries. GSMA, London.

18. World Bank (2017) Mainstreaming Gender in Water and Sanitation. Water and Sanitation Program Working Paper, World Bank, Washington, DC, USA.

19. Hansford F (2016) Gender Bias in Intra-Household Resource Allocation: Who Wins and Loses, Who Decides, and How Can Public Action Help.

20. Oduro AD, Deere CD, Catanzarite ZB (2015) Women's Wealth and Intimate Partner Violence: Insights from Ecuador and Ghana. Feminist Economics 21(2): 1-29.

21. ILO (2008) Can Low Income Countries Afford Basic Social Security? Social Security Policy Briefing No. 3. ILO, Geneva, Switzerland.

22.IMF (2007) World Economic Outlook: Globalization and Inequality. Washington, IMF, DC, USA.
23. Zachary B, Nelson K, Ray I (2016) Towards Gender Equality through Sanitation Access. Discussion Paper, UN Women, New York, USA.

24. De Henau J, S Himmelweit, Z Lapniewska, D Perrons (2016) Investing in the Care Economy: A Gender Analysis of Employment Stimulus in Seven OECD Countries. Brussels: International Trade Union Confederation, Belgium.

25. Duflo E (2012) Women Empowerment and Economic Development. Journal of Economic Literature 50(4): 1051-1079.

26. Dyson S (2012) Preventing Violence against Women and Girls: From Community Activism to Government Policy. Working Paper. Partners for Prevention, Bangkok.

27. UN Women (2017) Progress of the World's Women: In Pursuit of Justice. UN Women, New York, USA.

28. Ellsberg M, Arango DJ, Morton M, Gennari F, Sveinung K, et al. (2015) Prevention of Violence against Women and Girls: What Does the Evidence Say? The Lancet 385(9987): 1555-1566.

29. Budig M J, J Misra (2010) How Care-Work Employment Shapes Earnings in Cross-National Perspective. International Labour Review 149(4): 441-460.

30. Nicolai S, Hoy C, Berliner T, Aedy T (2015) Projecting Progress: Reaching the SDGs by 2030. London: Overseas Development Institute (ODI), UK.

31. Dayringer S (2015) In the 2017 High-Level Political Forum on Sustainable Development: Civil Society Plays Key Role in Voluntary National Reviews and Coherence. Global Policy Watch, USA.

32. Kabeer N (2003) Gender Mainstreaming in Poverty Eradication and the Millennium Development Goals: A Handbook for Policy-Makers and Other Stakeholders. Commonwealth Secretariat, London.

33. Zwingel S (2016) Translating International Women's Rights: The CEDAW Convention in Context. Palgrave Macmillan, London.

34. Sepúlveda M (2017) Gender-Responsive Accountability for the Implementation of the SDGs: The Potential of Using Existing Mechanisms and Procedures. Background paper for the Research and Data Section. UN Women. New York, USA.

35. Brody A (2016) Towards Gender-Just Food and Nutrition Security. BRIDGE Cutting Edge Programmes Policy Brief. Institute of Development Studies, Brighton, UK.

36. Sarwar M B (2015) National MDG implementation: Lessons for the SDG Era. Working Paper 428. Overseas Development Institute (ODI), London. 